\title{
Genetic Association Study of Angiotensin II Receptor Types 1 (A168G) and 2 (T1247G and A5235G) Polymorphisms in Breast Carcinoma among Brazilian Women
}

Maria del Carmen Garcia Molina Wolgiena Ismael Dale Cotrim Guerreiro da Silva ${ }^{a}$ Afonso Celso Pinto Nazário ${ }^{a}$ Clovis Riuche Nakaie ${ }^{b}$ Silvana Aparecida Alves Correa-Noronha ${ }^{c}$ Samuel Marcos Ribeiro de Noronha ${ }^{c}$ Gil Facina ${ }^{a}$

${ }^{a} G y n e c o l o g y$ Department, ${ }^{b}$ Biophisics Department, 'Surgery Department, Escola Paulista de Medicina/Universidade Federal de São Paulo (EPM-UNIFESP), Brazil

\section{Keywords}

Angiotensin II type 1 receptor - Angiotensin II type 2 receptor - Breast neoplasm - Genetic polymorphisms . Genotyping

\section{Summary}

Background: Many types of cancer are associated with polymorphisms of the renin-angiotensin system. Our aim was to assess possible association between singlenucleotide polymorphisms (SNPs) of the angiotensin II receptor types 1 (A168G), and 2 (T1247G and A5235G) with breast cancer. Patients and Methods: 242 participating subjects were genotyped and allocated to case or control groups. Results: Genotype distribution (in \%) was: for AGTR1 (A168G): AA, AG, GG = 61, 30, 09 for cases, and 69, 25, 06 for controls ( $p=0.55$ ); for AGTR2 (T1247G): TT, TG, GG = 84, 12, 04 for cases, and 81, 17, 02 for controls ( $p=0.45$ ); for AGTR2 (A5235G): AA, AG, $\mathrm{GG}=32,67,01$ for cases, and 53, 28, 19 for controls ( $p<0.0001$ ). Women carrying genotypes $A A / A G$ in the intronic region of angiotensin II type 2 receptor had an 11-fold higher risk of breast cancer than GG carriers. Conclusions: Many types of cancer have been associated with polymorphisms of the renin-angiotensin system. For SNP A5235G, the GG genotype seems to be protective against breast cancer. The other 2 SNPs showed no association. However, SNPs T1247G and A5235G were associated with at least 1 clinical variable, with $\mathrm{G}$ being a predictor of better outcome. The use of SNPs A5235G and T1247G (the latter to a lesser degree) as genetic markers should be considered.

\section{Introduction}

Angiotensin-converting enzyme 1 (ACE1) converts the inactive decapeptide angiotensin I (AngI) to the active octapeptide and potent vasoconstrictor angiotensin II (AngII), which is the main active product of the renin-angiotensin system (RAS) [1]. AngII accomplishes a variety of biological functions via $\mathrm{G}$ protein-coupled receptors, of which the angiotensin II type 1 receptor (AGTR1) is the predominant subtype expressed in most adult tissues [2]. AngII possesses characteristics of growth factors that induce effects such as hypertrophy and hyperplasia by activating the AGTR1 [3-5]. This agonist-receptor interaction also promotes angiogenesis, tumor metastasis [6], and breast cell proliferation [7], suggesting a function for AngII in the etiology or in the progression of cancer. These effects are observed in mammary cancer cells, in endothelial cells and in vascular smooth muscle $[4,8$, 9]. AGTR1 is expressed in the large majority of normal tissues and its expression frequently increases in the corresponding neoplastic tissues, demonstrating that the overexpression of this receptor is involved in carcinogenesis [10]. Use of ACE1 inhibitors and other antihypertensive medications has been associated with breast cancer risk [11-13]. Other evidence links ACE1 activity and AngII to breast cancer [14]. ACE $A 240 T$ and ACE $I / D$ polymorphisms have also been associated with breast cancer risk [15]. In a previous study, we observed that the ID genotype is less frequently associated with breast cancer than the DD and II genotypes. Among Brazilian women, ID carriers are 3.1 times less likely to develop breast cancer than those carrying the other genotypes. The ID genotype seems to be protective for breast cancer, and this association makes the ACE (I/D) polymorphism a possible target for developing genetic markers for both breast [16] and

\section{KARGER}

Fax +497614520714

Information@Karger.com

www.karger.com (c) 2014 S. Karger GmbH, Freiburg

$1661-3791 / 14 / 0093-0176 \$ 39.50 / 0$

Accessible online at:

www.karger.com/brc 
endometrial cancers, but not for ovarian cancer [17]. Besides the association of RAS with gynecological cancers, a recent meta-analysis study found that single-nucleotide polymorphism (SNP) ACE A-240T has the potential to become a genetic marker for lung cancer among Chinese people [18].

Breast cancer is thus known to be associated with some RAS components. However, so far, no data are available regarding the association of the SNPs AGTR1 (A168G) and AGTR2 (T1247G and A5235G) with breast cancer. In this study we aimed to investigate how these 3 SNPs, located in non-coding regions of the genes, could regulate the binding affinity of the transcription machinery to the promoter region of $A G T R 1$ and $A G T R 2$, as well as a possible interaction with mRNA transcript processing by alternative splicing mechanisms. In summary, our objective was to investigate how these genetic alterations could interfere with AngII signaling through AGTR1 and AGTR2 during breast carcinogenesis among Brazilian women through a case-control association study.

\section{Material and Methods}

\section{Subjects}

All samples were obtained after informed consent from the subjects prior to their inclusion in the study. 242 eligible women were included in the SNP AGTR1 or AGTR2 (A168G; T1247G; A5235G) groups (115 cases; 127 controls). All women allocated to case groups had their tumors surgically and histologically confirmed. The control group was composed of subjects with no prior history of breast cancer. Breast cancer case patients were admitted to and treated at the Mastology Section, Division of Gynecology and Obstetrics, Hospital Sao Paulo, Sao Paulo, Brazil. Control group women were admitted to the Menopause session/Gynecology Department of the Hospital Sao Paulo. Admissions occurred from March 2011 to December 2012. A structured questionnaire was applied to obtain detailed information on demographic factors, as well as menstrual and reproductive history. Clinical variables like TNM category and axillary lymph node status were also assessed in breast cancer patients.

\section{Ethics}

The procedures were performed in accordance with the ethical standards of the responsible committee on institutional human experi- mentation. The study protocol for the use of human subjects in research was approved by the local ethics committee (CEP/UNIFESP, Number 0424/09). The study thus met the standards of the Declaration of Helsinki in its revised version of 1975 and its amendments of 1983, 1989 and 1996.

\section{DNA Extraction}

Blood samples were collected and immediately stored at $-80{ }^{\circ} \mathrm{C}$ for subsequent genomic DNA extraction. DNA extraction was performed using a $\mathrm{GFX}^{\circledR}$ Kit for blood and tissue cells (GE HealthCare Life Sciences, Pittsburg, USA) according to the manufacturer's instructions.

\section{Genotyping}

The custom TaqMan ${ }^{\circledR}$ SNP genotyping assays (AGTR1), or TaqMan ${ }^{\circledR}$ SNP genotyping assays (AGTR2) (Applied Biosystems, Palo Alto, CA, USA) were used for allelic discrimination, with a 40× PCR mix (Applied Biosystems) specific to each SNP studied (AGTR1 A168G rs275653; AGTR2 T1247G rs5950584; A5235G rs1403543). The Assays-by-Design ${ }^{\text {SM }}$ service (Applied Biosystems) is an assay development service that designs, synthesizes, formulates, and delivers analytically quality-controlled primer and probe sets for SNP genotyping and gene expression assays based on sequence information (table 1) submitted by the customer. To obtain specific DNA sequence amplification, we employed a 7500 RealTime PCR system (Applied Biosystems) using $10 \mu \mathrm{l}$ TaqMan ${ }^{\circledR}$ Universal PCR Master Mix, No AmpErase ${ }^{\circledR}$ UNG $(2 \times), 0.5 \mu$ l specific assay mix (A168G, T1247G and A5235G) containing the primers and probes, 1-20 ng genomic DNA and sterile water for a total volume of $20 \mu \mathrm{l}$. PCR conditions were an additional step at $50{ }^{\circ} \mathrm{C}$ for $2 \mathrm{~min}$, and an initial step at $95{ }^{\circ} \mathrm{C}$ for $10 \mathrm{~min}$, followed by 40 cycles of denaturing at $92{ }^{\circ} \mathrm{C}$ for $15 \mathrm{~s}$ and annealing/extension at $60{ }^{\circ} \mathrm{C}$ for $1 \mathrm{~min}$. A negative control without template DNA was used in each run. The allelic discrimination was determined by analysis using SDS Software v. 1.3.1 (Applied Biosystems).

\section{Statistical Analysis}

Allele and genotype frequencies in patient and control groups were compared using the multiple person chi-squared test $\left(\chi^{2}\right.$ test) or the Fisher exact test. Odds ratio (OR) was estimated by the logistic regression model, assuming $95 \%$ as the confidence interval (CI), to measure the strength of the association between the frequencies of genotype and breast cancer. Values of $\mathrm{p}<0.05$ were considered statistically significant. Using standard $\chi^{2}$ statistics, we tested whether the allele frequencies deviated from the Hardy-Weinberg equilibrium (HWE). Data were analyzed using the computer software SPSS (Version 7.5) for Windows. For graphic constructs, we used the software GraphPad Prism ${ }^{\circledR}$ (Versions 5) and Excel for Windows XP ${ }^{\mathrm{TM}}$.

Table 1. Genomic sequences containing each SNP assessed through the custom TaqMan ${ }^{\circledR}$ SNP genotyping assays (AGTR1), Assays-by-Design service, or TaqMan ${ }^{\circledR}$ SNP genotyping assays (AGTR2) (Applied Biosystems)

\begin{tabular}{ll}
\hline Polymorphisms & Sequences with mutations used for TaqMan ${ }^{\circledR}$ SNP genotyping assays \\
\hline$A G T R_{1}$ A168G $(\mathrm{Chr} 3)$ & TGAACGCTGATCTGATAGTTGACACGGGACGACTGTGGCATCATCCTTGCTGCCGTCA[A/G] \\
(customized or on-demand assay) & TATCCCGAGAGGGAGGAGGTTGGGCCGGGAGGGTCTCCCGGGGCGGGGCGGAGGAGGAG \\
Gene ID: rs275653 & GGAATGCAAAACAGAGCCTCGA
\end{tabular}

\section{AGTR2-T1247G (Chr X)}

(pre-designed assay)

Gene ID: rs5950584

AGTR2-A5235G (Chr X intron)

(pre-designed assay)

Gene ID: rs1403543

SNP = single-nucleotide

polymorphism.
GACAGGAGTTTACGATATATT[T/G]GGTTGACCATTTTTTAA

TTAACACTGTATTTTGCAAAACTCCT[A/G]AATTATTTAGCTGCTGTTTCTCTTA 


\section{Results}

Among the 3 polymorphisms studied here, an association was only found between allelic distribution with case/control groups for SNP AGTR2 (A5235G). The SNPs of the AGTR2 were associated with at least 1 clinical variable, but there was no association of these variables with the AGTR1 polymorphism. A more detailed description of each SNP is given below.

We evaluated 242 women in this association study of SNPs AGTR1 or AGTR2 (A168G; T1247G; A5235G) with breast cancer: 115 were breast cancer patients and 127 were controls. The age of these patients ranged from 26 to 90 years. The mean age \pm SEM was $57 \pm 0.8$ years for cases and $55 \pm$ 0.7 years for controls, with no significant statistical difference between groups $(p=0.10)$. Likewise, there were no significant statistical differences between groups for the variables race and menopausal status (data not shown).

\section{AGTR1 (A168G) Polymorphism}

The frequency distribution of SNP AGTR1 (A168G) genotypes, wild-type AA, heterozygous AG, and polymorphic GG was as follows: breast cancer patients, $61 \%, 30 \%$, and $09 \%$; and control patients, $69 \%, 25 \%$, and $06 \%$ (table 2 ). We could not verify a statistically significant association between allelic distribution of this SNP with breast cancer $(p=0.55)$ as illustrated in table 2 .

We also carried out statistical analyses to investigate a possible association between the SNP with clinical variables, such as TNM category and axillary lymph node status, to assess whether this RAS-related SNP is associated with tumor progression (table 3). No association was observed between clinical variables and SNP AGTR1 (A168G) allelic distribution among breast cancer patients.

The allelic frequency was also verified for SNP AGTR1 (A168G). We observed that A and G alleles had the following distribution: 0.76 and 0.24 among case patients and 0.81 and 0.19 among control patients.

Table 2. Genotypic distributions of all RAS polymorphism between case (breast cancer) and control patients

\begin{tabular}{|c|c|c|c|c|c|}
\hline \multirow[t]{2}{*}{ Polymorphisms } & \multicolumn{4}{|c|}{ Groups } & \multirow[t]{2}{*}{$\mathrm{p}$} \\
\hline & \multicolumn{2}{|c|}{ Breast cancer } & \multicolumn{2}{|c|}{ Control } & \\
\hline \multicolumn{6}{|c|}{ AGTR1 (A168G) } \\
\hline AA & 70 & 61 & 87 & 69 & \\
\hline $\mathrm{AG}$ & 34 & 30 & 32 & 25 & 0.55 \\
\hline GG & 11 & 09 & 08 & 06 & $\chi^{2}=1.2$ \\
\hline \multicolumn{6}{|c|}{ AGTR2 (T1247G) } \\
\hline TT & 97 & 84 & 103 & 81 & \\
\hline TG & 14 & 12 & 22 & 17 & 0.45 \\
\hline GG & 04 & 04 & 02 & 02 & $\chi^{2}=1.58$ \\
\hline \multicolumn{6}{|c|}{ AGTR2 (A5235G) } \\
\hline AA & 37 & 32 & 67 & 53 & \\
\hline $\mathrm{AG}$ & 77 & 67 & 36 & 28 & $<0.0001 * * *$ \\
\hline GG & 01 & 01 & 24 & 19 & $\chi^{2}=37$ \\
\hline $\mathrm{AA} / \mathrm{AG}$ & 114 & 99 & 103 & 81 & $<0.0001 * * *$ \\
\hline GG & 01 & 01 & 24 & 19 & $\chi^{2}=18(95 \% \mathrm{CI}=1.6-74), \mathrm{OR}=23, \mathrm{RR}=11$ \\
\hline
\end{tabular}

$\mathrm{RAS}=$ renin-angiotensin system, $\mathrm{OR}=$ odds ratio; $\mathrm{RR}=$ relative risk. $\mathrm{CI}=$ confidence interval.

*Statistically significant difference; $\chi^{2}$ test with $\mathrm{p}<0.05$.

Table 3. Clinical characteristics of breast cancer patients (cases, $n=115$ ) according to AGTR1 and AGTR2 genotypes and statistical analysis of the variables

\begin{tabular}{|c|c|c|c|c|c|c|}
\hline \multirow[t]{2}{*}{ Polymorphisms } & \multicolumn{2}{|c|}{ TNM category, $\mathrm{n}(\%)$} & \multirow[b]{2}{*}{$\mathrm{p} \#$} & \multicolumn{2}{|c|}{ Axillary lymph node status, n (\%) } & \multirow[b]{2}{*}{$\mathrm{p \#}$} \\
\hline & $\mathrm{I} / \mathrm{II}$ & III/IV & & No & Yes & \\
\hline $\begin{array}{l}\text { AGTR1 (A168G) } \\
\text { AA } \\
\text { AG } \\
\text { GG }\end{array}$ & $\begin{array}{l}76(66) \\
81(70) \\
73(64)\end{array}$ & $\begin{array}{l}39(34) \\
34(30) \\
72(36)\end{array}$ & $\begin{array}{l}0.66 \\
\chi^{2}=0.84\end{array}$ & $\begin{array}{l}64(56) \\
66(58) \\
59(51)\end{array}$ & $\begin{array}{l}51(44) \\
49(42) \\
56(49)\end{array}$ & $\begin{array}{l}0.50 \\
\chi^{2}=1.4\end{array}$ \\
\hline $\begin{array}{l}\text { AGTR2 (T1247G) } \\
\text { TT } \\
\text { TG } \\
\text { GG }\end{array}$ & $\begin{array}{l}86(75) \\
99(86) \\
66(57)\end{array}$ & $\begin{array}{l}26(25) \\
16(14) \\
49(43)\end{array}$ & $\begin{array}{l}<0.0001^{* * *} \\
\chi^{2}=21\end{array}$ & $\begin{array}{l}67(58) \\
28(24) \\
14(13)\end{array}$ & $\begin{array}{r}48(42) \\
87(76) \\
101(87)\end{array}$ & $\begin{array}{l}<0.0001 * * * \\
\chi^{2}=51\end{array}$ \\
\hline $\begin{array}{l}\text { AGTR2 (A5235G) } \\
\text { AA } \\
\text { AG } \\
\text { GG }\end{array}$ & $\begin{array}{l}67(58) \\
81(70) \\
76(66)\end{array}$ & $\begin{array}{l}48(42) \\
34(30) \\
39(34)\end{array}$ & $\begin{array}{l}0.20 \\
\chi^{2}=3.3\end{array}$ & $\begin{array}{l}29(25) \\
51(44) \\
60(52)\end{array}$ & $\begin{array}{l}86(75) \\
64(56) \\
55(48)\end{array}$ & $\begin{array}{l}0.0003^{* * * *} \\
\chi^{2}=16\end{array}$ \\
\hline
\end{tabular}

*Statistically significant difference; $\chi^{2}$ test with $\mathrm{p}<0.05$. 
Table 4. Hardy-Weinberg equilibrium (HWE) for AGTR1 and AGTR2 polymorphisms in the case and control groups according to expected (E) and observed $(\mathrm{O})$ values

\begin{tabular}{|c|c|c|c|c|c|c|c|c|c|c|}
\hline & \multicolumn{3}{|c|}{ Cases, n (\%) } & \multirow[t]{2}{*}{$\begin{array}{l}\text { Total, } \\
\text { n (\%) }\end{array}$} & \multirow[t]{2}{*}{$\begin{array}{l}\text { HWE } \\
p \text { value }\end{array}$} & \multicolumn{3}{|c|}{ Controls, n (\%) } & \multirow[t]{2}{*}{$\begin{array}{l}\text { Total, } \\
\text { n (\%) }\end{array}$} & \multirow[t]{2}{*}{$\begin{array}{l}\text { HWE } \\
\text { p value }\end{array}$} \\
\hline \multicolumn{7}{|c|}{ AGTR1 (A168G) } & & & & \\
\hline & AA & $\mathrm{AG}$ & GG & & & AA & $\mathrm{AG}$ & GG & \multirow{5}{*}{$\begin{array}{l}127(100) \\
127(100)\end{array}$} & \multirow{5}{*}{$\begin{array}{l}\chi^{2}=1.48 \\
p=0.48\end{array}$} \\
\hline $\mathrm{O}$ & $70(61)$ & $34(30)$ & $11(09)$ & $115(100)$ & $\chi^{2}=1.22$ & $87(69)$ & $32(25)$ & $08(06)$ & & \\
\hline $\mathrm{E}$ & $67(58)$ & $41(36)$ & $07(06)$ & $115(100)$ & $\hat{p}=0.54$ & $85(67)$ & $38(30)$ & $04(03)$ & & \\
\hline \multicolumn{9}{|c|}{ AGTR2 (A1247) } & & \\
\hline & TT & TG & GG & & & TT & TG & GG & & \\
\hline $\mathrm{O}$ & $97(84)$ & $14(12)$ & $04(04)$ & $115(100)$ & $\chi^{2}=3.1$ & $103(81)$ & $22(17)$ & $02(02)$ & \multirow{4}{*}{$\begin{array}{l}127(100) \\
127(100)\end{array}$} & \multirow{4}{*}{$\begin{array}{l}\chi^{2}=1.5 \\
p=0.47\end{array}$} \\
\hline $\mathrm{E}$ & $93(81)$ & $21(18)$ & $01(01)$ & $115(100)$ & $p=0.22$ & $94(74)$ & $30(24)$ & $03(02)$ & & \\
\hline \multicolumn{9}{|c|}{ AGTR2 (A5235G) } & & \\
\hline & AA & $\mathrm{AG}$ & GG & & & AA & $\mathrm{AG}$ & GG & & \\
\hline $\mathrm{O}$ & $01(01)$ & $77(67)$ & $37(32)$ & $115(100)$ & $\chi^{2}=15$ & $24(19)$ & $36(28)$ & $67(53)$ & $127(100)$ & \multirow{2}{*}{$\begin{array}{l}\chi^{2}=6.3 \\
p=0.04^{*}\end{array}$} \\
\hline E & 14 (12) & $53(46)$ & $48(42)$ & $115(100)$ & $p=0.0007$ & $14(11)$ & $57(44)$ & $56(45)$ & $127(100)$ & \\
\hline
\end{tabular}

Finally, we performed an HWE test and observed that allelic frequency was balanced among case and control groups. The HWE test confirmed that the genotypic frequencies did not diverge significantly from the equilibrium in either case and control groups ( $p=0.54$ and 0.48$)$ (table 4$)$.

\section{AGTR2 (T1247G) Polymorphism}

The frequency distribution of the SNP AGTR2 (T1247G) genotypes, wild type (TT), heterozygous (TG) and polymorphic (GG) was as follows: breast cancer patients, $84 \%, 12 \%$ and $04 \%$; and control patients, $81 \%, 17 \%$ and $02 \%$ (table 2 ). We could not verify a statistically significant association between allelic distribution of this SNP with breast cancer $(\mathrm{p}=0.45)$, as illustrated in table 2 .

For the SNP AGTR2 (T1247G)-breast cancer association study, we performed the same statistical analyses as described for the SNP AGTR1 (A168G), i.e. allelic distribution versus clinical variables. In SNP AGTR2 (T1247G), we observed an association between allelic distribution and both TNM category and axillary lymph node status $(\mathrm{p}<0.0001)$. This suggests a strong association with tumor progression (table 3 ), with the polymorphic GG genotype being a predictor of poor outcome for both variables. The $\mathrm{G}$ allele seemed to be more strongly associated with axillary lymph node metastasis than with TNM category (table 3 ).

The allelic frequency was also verified for SNP AGTR2 (T1247G). We observed that $\mathrm{T}$ and $\mathrm{G}$ alleles had the following distribution: 0.90 and 0.10 among case patients, and 0.90 and 0.10 among control patients.

Finally, we performed an HWE test and observed that allelic frequency was balanced among case and control groups. The HWE test confirmed that the genotypic frequencies did not diverge significantly from equilibrium in either the case and control groups ( $p=0.22$ and 0.47 ) (table 4).

\section{AGTR2 (A5235G) Polymorphism}

The frequency distribution of SNP AGTR2 (A5235G) genotypes wild-type AA, heterozygous $\mathrm{AG}$ and polymorphic
GG was as follows: breast cancer patients, $32 \%, 67 \%$ and $01 \%$; and control patients, $53 \%, 28 \%$ and $19 \%$ (table 2). By analyzing the frequency of polymorphism of the AGTR2 receptor gene $(\mathrm{A} 5235 \mathrm{G})$ among patients with breast cancer and control patients, we observed a statistically significant difference between the 2 groups $(\mathrm{p}<0.0001 * * *)$, as illustrated in table 2, with $\mathrm{AA} / \mathrm{AG}$ carriers being more likely to be diagnosed with breast cancer than polymorphic GG carriers (11 times).

The allelic frequency was also verified for SNP AGTR2 (A5235G). A and $\mathrm{G}$ alleles had the following distribution: 0.35 and 0.65 among case patients, and 0.33 and 0.67 among control patients.

In the statistical analyses of allelic distribution versus clinical variables, in SNP AGTR2 (A5235G), we only observed association between allelic distribution and axillary lymph node status ( $p=0.0003^{* * *}$ ), in which the genotype GG might be considered a predictor of a better prognosis, and allele A may be linked to a more aggressive type of cancer (table 3 ).

Finally, we performed an HWE test and observed that allelic frequency diverged significantly from equilibrium in both the case and control groups ( $\mathrm{p}=0.0007 * * *$ and $0.04 *)$ (table 4).

\section{Discussion}

The present study is the first to investigate a possible association between the SNPs AGTR1 (A168G) and AGTR2 (T1247G and A5235G) with breast cancer among Brazilian women. AGTR1 is located in chromosome 3q21-25, and has 5 exons. Its expression is regulated by the binding accessibility of the transcription machinery to the 5' flanking region of the gene. AGTR2 is located in chromosome $\mathrm{Xq} 23$, and has 3 exons. Exon 3 contains the entire open reading frame.

Previous results suggested that blockade of AngII signaling through AGTR1 might be protective against breast cancer. To test the hypothesis that AngII participates in breast car- 
cinogenesis through AGTR1 signaling, Koh and colleagues [19] focused on SNPs in the 5' region of AGTR1, such as SNP AGTR1 (A168G), and their possible association with breast cancer. However, as in the present study, Koh and colleagues did not find any association between SNP AGTR1 (A168G) and breast cancer.

In addition, according to our results, the non-coding SNPs AGTR2 (T1247G) and (A5235G) were associated with at least 1 of the clinical variables considered in these breast cancer patient populations. Interestingly, SNP AGTR2 (T1247G) was not associated with cancer risk; however associations were found with both clinical variables (in contrast to the other 2 SNPs studied: AGTR2 (A5235G) was associated with only 1 clinical variable and AGTR1 (A168G) was associated with neither). For SNP AGTR2 (A5235G), allele G was associated with cancer risk and progression, which, combined, demonstrates that this SNP may be relevant for designing detection and therapeutic approaches for the disease. In addition, although SNP AGTR2 (T1247G) was not associated with cancer risk, there was an association with both clinical variables, and the $G$ allele was observed in patients with a more aggressive type of cancer, particularly when axillary lymph node invasion was considered [20]. In general, these results strongly suggest that these SNPs, as parts of complex gene interactions, are linked to breast cancer risk and might be playing an important role in the disease progression.

Several studies support the significant association of AGTR2 signaling with various types of cancer (renal, colorectal, prostate, uterine, breast and pancreatic) [7, 21-25]. Initially, the 2 AGTR2 SNPs studied here were only associated with the circulatory system or with metabolism and nutrition disorders [26]. From our results it is clear that, although SNP AGTR2 (T1247G) is not associated with breast cancer, SNP
AGTR2 (A5235G), located in the intronic region (like ACE1 ID polymorphism) of $A G T R 2$, is associated with the disease, and that the allele $\mathrm{G}$ may be protective. The association suggests that SNP A5235G might alter susceptibility to the disease.

In conclusion, accumulating evidence suggests that the RAS is implicated in the development and in the invasion of several kinds of cancer [27]. The present study provides another piece of evidence that RAS-related receptor signaling, especially the AGTR2, might interfere with breast cancer incidence and also with its progression. Moreover, genetic predisposition to cancer is determined by a complex combination of many components within the cellular context. Certainly, within this breast cancer cellular context, although it is very heterogeneous between different subtypes, an important role is played by the set of SNPs that everyone carries in their genome. In this study, we showed that non-coding RAS-related SNPs were associated with cancer risk and progression. We believe that the use of SNPs AGTR2 (A5235G) and AGTR2 (T1247G) (the latter to a lesser degree) could be used as predictors for breast cancer risk among Brazilian women.

\section{Acknowledgements}

This work was supported by the Sao Paulo State Research Foundation (FAPESP) through grants numbers 2007/56480-0, 2008/50776-7, and 2008/54383-0.

\section{Disclosure Statement}

The authors declare that there are no conflicts of interest.

\section{References}

1 Sayed-Tabatabaei FA, Oostra BA, Isaacs A, et al.: ACE Polymorphisms. Circ Res 2006;98:1123-1133.

$\checkmark 2$ de Gasparo M, Catt KJ, Inagami T, et al.: International union of pharmacology. XXIII. The angiotensin II receptors. Pharmacol Rev 2000;52:415472.

-3 Wolf G, Ziyadeh FN, Helmchen U, et al.: ANG II is a mitogen for a murine cell line isolated from medullary thick ascending limb of Henle's loop. Am J Physiol 1995;268:F940-947.

4 Stoll M, Meffert S, Stroth U, Unger T: Growth or antigrowth: Angiotensin and the endothelium. J Hypertens 1995;13:1529-1534.

5 Tian Y, Balla T, Baukal AJ, Catt KJ: Growth responses to angiotensin II in bovine adrena glomerulosa cels. Am J Physiol 1995;268:E135-144.

6 Fujita M, Hayashi I, Yamashina S, et al.: Blockade of angiotensin AT1a receptor signaling reduce tumor growth, angiogenesis, and metastasis. Biochem Biophys Res Commun 2002;294:441-447.

7 Muscella A, Greco S, Elia MG, et al.: Angiotensin II stimulation of $\mathrm{Na}^{+} / \mathrm{K}^{+}$-ATPase activity and cell growth by calcium-independent pathway in MCF-7 breast cancer cells: J Endocrinol 2002;173:315-323.
8 Nakajima M, Hutchinson HG, Fujinaga M, et al.: The angiotensin II type 2 (AGTR2) receptor antagonizes the growth effects of the $\mathrm{AT}_{1}$ receptor: Gain of function study using in vivo gene transfer: Proc Natl Acad Sci USA 1990;92:10663-10667.

9 De Paepe B, Verstraeten VL, De Potter CR, et al.: Increased angiotensin II type-2 receptor density in hyperplasia. DCIS and invasive carcinoma of the breast is paralleled with increased iNOS expression. Histochem Cell Biol 2002;116:247-254

10 Marsigliante S, Resta L, Muscella A, et al.: AT angiotensin II receptor subtype in the human laryns and squamous laryngeal carcinoma. Cancer Lett 1996;110:19-27.

11 Mack TM, Henderson BE, Gerkins VR, et al.: Reserpine and breast cancer in a retirement community. N Engl J Med 1975;292:1366-1371.

12 Lever AF, Hole DJ, Gillis CR, et al.: Do inhibitors of angiotensin-I-converting enzyme protect against risk of cancer? Lancet 1998;352:179-184.

13 Meier CR, Derby LE, Jick SS, Jick H: Angiotensinconverting enzyme inhibitors, calcium channel blockers, and breast cancer. Arch Intern Med 2000; 160:349-353
14 Koh WP, Yuan JM, Sun CL, et al.: Angiotensin Iconverting enzyme (ACE) gene polymorphism and breast cancer risk among Chinese women in Singapore. Cancer Res 2003;63:573-578.

15 Haiman CA, Henderson SO, Bretsky P, et al. Genetic variation in angiotensin I-converting enzyme (ACE) and breast cancer risk: The multiethnic cohort. Cancer Res 2003;63:69846987.

16 Alves Corrêa SA, Ribeiro de Noronha SM, Nogueira-de-Souza NC, et al.: Association between the angiotensin-converting enzyme (insertion/deletion) and angiotensin II type 1 receptor (A1166C) polymorphisms and breast cancer among Brazilian women. J Renin Angiotensin Aldosterone Syst 2009;10:51-58.

17 Correa-Noronha SA, Ribeiro de Noronha SM, Alecrim C, et al.: Association of angiotensin-converting enzyme I gene I/D polymorphism with endometrial but not with ovarian cancer. Gynecol Endocrinol 2012;28:889-891.

18 Gao M, Wang Y, Shi Y, et al.: The relationship between three well-characterized polymorphisms of the angiotensin converting enzyme gene and 
lung cancer risk: A case-control study and a metaanalysis. J Renin Angiotensin Aldosterone Syst 2012;13:455-460.

19 Koh WP, Yuan JM, Van Den Berg D, et al.: Polymorphisms in angiotensin II type 1 receptor and angiotensin I-converting enzyme genes and breast cancer risk among Chinese women in Singapure. Carcinogenesis 2005;26:459-464.

20 Karanikolić A, Djordjević N, Filipovicz S, et al.: Axillary recurrence after modified radical mastectomy. Acta Chir Iugosl. 2005;52:39-43.
21 Dolley-Hitze T, Jouan F, Martin B, et al.: Angiotensin-2 receptors (AT1-R and AT2-R), new prognostic factors for renal clear-cell carcinoma? Br J Cancer 2010;103:1698-1705.

22 Neo JH, Ager EI, Angus PW, et al.: Changes in the renin angiotensin system during the development of colorectal cancer liver metastases. BMC Cancer 2010;10:134.

23 Bose SK, Gibson W, Giri S, et al.: Angiotensin II up-regulates PAX2 oncogene expression and activity in prostate cancer via theangiotensin II type I receptor. Prostate 2009;69:1334-1342.
24 Tahmasebi M, Puddefoot JR, Inwang ER, Vinson GP: The tissue renin-angiotensin system in human pancreas. J Endocrinol 1999;161:317-322.

25 Gallagher PE, Cook K, Soto-Pantoja D, et al.: Angiotensin peptides and lung cancer. Curr Cancer Drug Targets. 2011;11:394-404.

26 Seip RL, Volek JS, Windemuth A, et al.: Physiogenomic comparison of human fat in response to diets restrictive of carbohydrate or fat. Nutr Metab (Lond) 2008;5:4

7 Uemura H, Kubota Y: Cancer and renin-angiotensin system. Nihon Rinsho 2012;70:1530-1535. 